\title{
Unemployment durations and the pattern of duration dependence over the business cycle of British males
}

\author{
Adriaan Kalwij
}

Received: 9 July 2007 / Accepted: 19 January 2009 / Published online: 7 March 2009

(C) The Author(s) 2009. This article is published with open access at Springerlink.com

\begin{abstract}
This paper examines the relationship between the business cycle and individuals' duration in unemployment. I use multi-spell unemployment duration data of British males and monthly series of regional vacancies over unemployment, referred to as labour market tightness, to control for the business cycle. In line with most previous studies I find that the observed negative duration dependence on an aggregate level is explained by both sorting and strong negative individual duration dependence, and that the individual hazard of leaving unemployment increases with labour market tightness. The new empirical findings emerge from the interactions between individual duration dependence and the business cycle. Individual heterogeneity, and in particular the variation over the business cycle in the composition of the newly unemployed, explains most of the systematic variation over the business cycle in duration dependence on an aggregate level. Individual duration dependence does not vary over the business cycle in a way that would lend support to the predictions concerning this of the matching model of Lockwood (Rev Econ Stud 58:733-753, 1991) or the ranking model of Blanchard and Diamond (Rev Econ Stud 61:417-434, 1994).
\end{abstract}

Keywords Unemployment · Duration model · Business cycles

JEL Classification $\quad \mathrm{J} 64 \cdot \mathrm{C} 41 \cdot \mathrm{E} 32$

\footnotetext{
A. Kalwij $(\bowtie)$

Utrecht School of Economics, Utrecht University, Janskerkhof 12, 3512 BL Utrecht, The Netherlands e-mail: a.s.kalwij@uu.nl
}

\section{A. Kalwij}

Network for Studies on Pensions, Aging and Retirement, Tilburg University, Tilburg, The Netherlands 


\section{Introduction}

The relationship between individuals' duration in unemployment and the business cycle is of prime importance in the determination of aggregate unemployment dynamics (Layard et al. 1991). To gain insights in this relationship this paper presents detailed and new empirical evidence for Britain on how an individual's hazard of leaving unemployment is affected by the duration in unemployment (i.e. individual duration dependence), individual heterogeneity and the business cycle. In particular, this paper significantly contributes to the empirical literature by analysing in detail how individual duration dependence varies over the business cycle. Identifying this variation yields important insights for policymakers in the extent to which the long-term unemployed benefit from a tight labour market, i.e. when there are many vacancies relative to the number of unemployed. For instance, if the long-term unemployed benefit less than the short-term unemployed from a tight labour market then policy aimed at getting the long-term unemployed back into employment should be intensified when the labour market is tightening.

The empirical analysis makes use of a large administrative dataset containing multi-spell unemployment duration data of British males from April 1987 to September 1996. Monthly series of regional vacancies over unemployment are used to control for the business cycle and this variable is referred to as labour market tightness. The multi-spell nature of the data yields the main contribution to the literature as this makes it possible to identify the interactions between individual duration dependence and labour market tightness when modelling the hazard of leaving unemployment. Previous UK studies addressing this issue employ either single-spell duration data or aggregate data.

Lockwood (1991) and Blanchard and Diamond (1994) present theoretical economic models explaining the relationship between individuals' duration in unemployment and labour market tightness. The ranking model of Blanchard and Diamond (1994) assumes that an employer ranks applicants by their unemployment durations and hires the one with the shortest duration. This ranking model predicts an increase in an individual's hazard of leaving unemployment with labour market tightness, negative individual duration dependence and, moreover, that the predicted negative individual duration dependence is weaker the tighter the labour market. The latter result comes from the fact that the tighter the labour market, the lower the ratio of applications to vacancies, the more likely the long-term unemployed is the sole applicant, and, as a consequence of the ranking strategy, the more likely the long-term unemployed is hired. The matching model of Lockwood (1991) considers firms imperfectly testing workers before hiring them. In his model unemployment duration is a signal of productivity and, consequently, predicts that in equilibrium, if it is profitable for a firm to test, it is also profitable for firms to base their hiring decision on unemployment duration. The matching model of Lockwood (1991) predicts an increase in an individual's hazard of leaving unemployment with labour market tightness, negative individual duration dependence and, due to this discriminative behaviour of firms, that negative individual duration dependence is stronger the tighter the labour market. This latter result comes from the fact that a long spell of unemployment is more of a bad signal to a firm when there are many vacancies relative to the number unemployed (in a tight labour market). 
To summarize, the matching model of Lockwood (1991) and the ranking model of Blanchard and Diamond (1994) both predict an increase in an individual's hazard of leaving unemployment with labour market tightness and negative individual duration dependence but yield opposite predictions concerning the variation over the business cycle in individual duration dependence. The empirical analysis in this paper examines these predictions. This makes it possible to discriminate between the two theoretical economic models of Lockwood (1991) and Blanchard and Diamond (1994) that are both aimed at explaining unemployment durations over the business cycle.

The empirical literature on unemployment duration unambiguously shows that the aggregate hazard of leaving unemployment for British males decreases with unemployment duration (Layard et al. 1991; Van den Berg and Van Ours 1994; Turon 2003). ${ }^{1}$ This so-called negative duration dependence can be explained by both sorting and negative individual duration dependence. Sorting refers to a dynamic selection mechanism based on a relationship between individual heterogeneity and the hazard of leaving unemployment. For instance, heterogeneity can relate to job performance and those perceived to be most productive are hired first (Salant 1977) or to the effectiveness of jobseekers (Jackman and Layard 1991). Negative individual duration dependence may be caused by, for instance, a loss of skills (Pissarides 1992) or stigma effects (Vishwanath 1989; Jackman and Layard 1991) and identifying individual duration dependence is therefore of special interest to policymakers. If there is negative individual duration dependence policy should be aimed at preventing individuals from becoming long-term unemployed and should start as early as possible (e.g. assisted job search). If sorting plays a role policy should be aimed at increasing the employability of the unemployed (e.g. educational programs). Using aggregate British data, Van den Berg and Van Ours (1994) and Turon (2003) conclude that for British males individual heterogeneity plays no significant role in explaining negative duration dependence, i.e. there are no sorting effects. Using individual level British data, Nickell (1979), Lancaster (1979) and Narendranathan and Stewart (1993a) show the importance of observed heterogeneity, such as age and educational attainment, and unobserved (timeconstant) heterogeneity for explaining the probability of leaving unemployment. In line with these latter findings, the analysis in this paper identifies significant sorting effects due to individual heterogeneity and furthermore shows that this accounts for about one-third of the observed decrease in the hazard of leaving unemployment with duration within the first 2 years of unemployment on an aggregate level. Negative individual duration dependence explains the remaining two-thirds of this decrease. Strong negative individual duration dependence is a common finding in British studies and is in line with both the matching model of Lockwood (1991) and the ranking model of Blanchard and Diamond (1994).

The variation over the business cycle in the composition of the newly unemployed with respect to their employability is referred to as inflow heterogeneity. Darby et al. (1985) argue that in a situation of a loose labour market, i.e. few vacancies relative to the number of unemployed, the newly unemployment have relatively lower probabilities of leaving unemployment (lower employability). This is referred to as

\footnotetext{
1 Similar observations are recorded for other countries; see, e.g., Abbring et al. $(2001,2002)$ for the US and France and Cockx and Dejemeppe (2005) for Belgium.
} 
pro-cyclical inflow heterogeneity. Darby et al. (1985) claim that the main reason for longer unemployment durations during an economic recession is pro-cyclical inflow heterogeneity. Turon (2003), using aggregate data, concludes that in Britain inflow heterogeneity is counter-cyclical. The analysis in this paper also identifies countercyclical inflow heterogeneity and this is not in support the claim of Darby et al. (1985). ${ }^{2}$

The empirical evidence for Britain concerning the variation over the business cycle in the hazard of leaving unemployment points to an increase in the probability of leaving unemployment with labour market tightness, i.e. pro-cyclical sensitivity (Jackman and Layard 1991; Narendranathan and Stewart 1993b; Arulampalum and Stewart 1995; Turon 2003; Kalwij 2004). ${ }^{3}$ The analysis in this paper confirms that the individual hazard of leaving unemployment increases with labour market tightness. This finding is in line with both the matching model of Lockwood (1991) and the ranking model of Blanchard and Diamond (1994).

The empirical evidence on the variation over the business cycle in individual duration dependence is scarce, inconclusive and is mostly examined using US data (Dynarski and Sheffrin 1990; Imbens and Lynch 1993). ${ }^{4}$ For Britain, and both using aggregate data, Jackman and Layard (1991) conclude there are no systematic effects and Turon (2003) finds that negative duration dependence is weaker the tighter the labour market but that this effect is insignificant. In contrast to these findings the analysis in this paper shows that negative duration dependence on an aggregate level is somewhat stronger the tighter the labour market at short durations and is weaker the tighter the labour market at long durations. This in line with the US evidence reported in Abbring et al. (2001). However, the analysis in this paper furthermore shows that most of this systematic variation on an aggregate level is explained by individual heterogeneity and in particular by the variation over the business cycle in the unobserved composition of the newly unemployed (inflow heterogeneity). After controlling for individual heterogeneity, individual duration dependence does not vary over the business cycle in a way that would lend support to the predictions concerning this of the matching model of Lockwood (1991) or the ranking model of Blanchard and Diamond (1994). Moreover I show that when controlling for individual heterogeneity but not for inflow heterogeneity, as is often the case in empirical research, one can mistakenly conclude that there is empirical evidence in favour of negative individual duration dependence being weaker the tighter the labour market, as predicted by the ranking model of Blanchard and Diamond (1994) and reported in, for instance, Dynarski and Sheffrin (1990) for the US.

This paper is organized as follows. Section 2 describes the data. Section 3 formulates the econometric model. Section 4 reports and discusses the estimation results and Sect. 5 summarizes.

\footnotetext{
2 For the US Baker (1992) and Abbring et al. (2001) also find no support for this claim.

3 A similar finding is reported for the US (Sider 1985; Butler and McDonald 1986; Dynarski and Sheffrin 1990; Baker 1992; Abbring et al. 2001), for France (Van den Berg and Van der Klaauw 2001) and Denmark (Rosholm 2001).

4 Rosholm (2001) presents evidence for Denmark and Abbring et al. (2002) for France.
} 


\section{The data}

This section describes the data I use for the empirical analysis. Section 2.1 discusses the sampling procedure, defines unemployment and the observed variables in the data. Section 2.2 discusses the sample selection procedure and Sect. 2.3 presents descriptive statistics.

\subsection{The Joint Unemployment and Vacancy Operating System (JUVOS)}

The empirical analysis makes use of rather unique data, taken from the Joint Unemployment and Vacancy Operating System (JUVOS). The JUVOS is a longitudinal database of a five percent sample of all claims for unemployment related benefits paid through the National Unemployment Benefits System in Britain since 1982 and is updated daily using information supplied by the Employment Service local offices. Unemployment related benefit claims in Northern Ireland are included only from 1994 onwards. Sampling is based on a claimant's National Insurance number and yields a random and representative (stock) sample of the unemployed population in Britain at any day of the year. The data available for this paper are only one-fifth of the JUVOS data up to 1999, which amounts to a one percent random sample of all unemployment related benefits claims. A claim of an individual is included in the sample if the individual has a National Insurance number that ends in a specific pair of digits and is in unemployment during the observation period. An individual is continuously followed over the years (1982-1999) and included in the JUVOS whenever claiming unemployment related benefits. Of this sample I select the unemployment spells that started during the observation period. This yields a representative (flow) sample of the unemployed population in Britain who entered unemployment at any time during the observation period. The sampling scheme is based on the National Insurance number and this makes it possible to follow the same individual over the years, hence creating multiple spell observations for individuals entering unemployment more than once. For more background information on the JUVOS I refer to Ward and Bird (1995) and Sweeney (1996), and to Kalwij (2004) for a description of lifecycle unemployment experiences for a selective group of young British males. Van den Berg and Van Ours (1994) and Turon (2003) also make use of JUVOS data but on an aggregate level.

Using the JUVOS data defines unemployment as claiming unemployment related benefits. Individuals who become unemployed are entitled to benefits up to 12 months if they have paid enough National Insurance contributions. These insurance-based benefits are not means tested. Individuals who are not entitled to these benefits or individuals who exhaust these benefits are eligible for means tested benefits nowadays known as Income Based Job Seekers Allowance (JSA). This allowance is part of the UK welfare system and, as long as the means tested criteria is met, has an indefinite duration. JUVOS registers when an individual receives JSA.

JUVOS records consist of the start and end date of a claim. The JUVOS has complete information on individuals' gender, date of birth and marital status, and the region in which the claim is made. The ten regions considered are South East (including Greater London), South West, East Anglia, East Midlands, West Midlands, 
North West, Yorkshire and Humberside, North, Scotland and Wales. Information on marital status allows for the distinction between single (including widowed and divorced) and married (including cohabitating). As is often the case with administrative data, only limited information is available on individuals' characteristics. For instance, the level of education and work experience are not observed and extending the empirical work by using information on the human capital accumulation of an individual with age is considered a very important avenue for future research. Although the absence of information on individuals' human capital may limit the issues one wishes to examine, a very important advantage of the JUVOS data is that many individuals are observed over a long time period, creating multi-spell observations. This makes it possible to thoroughly examine the variation over the business cycle in individual duration dependence of the hazard of leaving unemployment.

\subsection{Sample selection}

Since 1982 several labour market programs have been initiated to get the unemployed back into work. Examples are the Youth Training Scheme that was introduced in 1983 (Dolton et al. 1994) and the in 1987 introduced Restart programme to monitor more closely the long-term unemployed (Dolton and O'Neill 1996). Also the period of entitlement for unemployment benefits has been reduced from a maximum of 12 months to a maximum of 6 months for individuals who enter unemployment from October 1996 onwards. In April 1998 the New Deal program has been implemented (Bell et al. 1999). These policy interventions were intended to affect individuals' unemployment durations. It is not an aim of this paper to predict how these may have affected, for instance, the pattern of individual duration dependence over the business cycle. The data in this paper do not identify participation in job search or training programs and can therefore not control for program participation. I therefore select the best I can a homogenous sample with respect to the policy-environment, hereby taking into account that a sufficiently long period is needed to identify cyclical effects in the unemployment durations. I therefore select the sample period that starts when the Restart programme was effective and ends when the maximum duration of benefit entitlement was reduced from 12 to 6 months. Thus I select unemployment spells that started in or after April 1987 and in or before September 1996. I censor all unemployment spells that continue after September 1996. The conclusions of this paper, however, appear rather insensitive to selecting different time periods. ${ }^{5}$ The resulting sample is a representative flow sample of unemployment spells over the period April 1987 to September 1996. This period covers an entire business cycle.

A further selection is that I restrict the sample to men aged 18 to 59 years. The 1988 Social Security Act changed the benefit entitlements of individuals younger than 18 and to receive benefits they no longer need to sign on as unemployed. Many unemployed women with a partner who is an earner are unlikely to be entitled to Income Based Job Seekers Allowance after exhausting benefits and therefore leave

\footnotetext{
5 For instance, for a comparison using the period 1982IV-1998II refer to a previous version (Kalwij 2001). In this previous version I use a somewhat different empirical specification but the main conclusions are the same as in this paper.
} 
Table 1 Frequency distribution of the number of multiple unemployment spells

\begin{tabular}{lllllllllll}
\hline Number of spells & 1 & 2 & 3 & 4 & 5 & 6 & 7 & 8 & 9 & $>9$ \\
\hline$\%$ of men & 40.0 & 22.0 & 13.5 & 8.8 & 5.6 & 3.6 & 2.3 & 1.6 & 0.9 & 1.7 \\
\hline
\end{tabular}

the JUVOS without actually having found employment. Van den Berg and Van Ours (1994) also conclude that JUVOS data of British females are 'unreliable' for the analysis of unemployment durations. For unemployed men this issue does not seriously affect the unemployment count (Nickell 1999).

\subsection{Descriptive statistics 6}

The sample used for the empirical analysis contains information on men aged 18-59 years who became at least one time unemployed between April 1987 and September 1996. In total 83,388 men make up for 222,901 spells of unemployment. $5.8 \%$ of the spells are right-censored. Table 1 shows that $60 \%$ of the men in the sample experience more than one spell of unemployment during the observation period.

Figure 1 shows the (aggregate) hazard of leaving unemployment and the survival function for up to 30 months in unemployment. For this descriptive purpose I estimate the model of Sect. 3 and control only for the duration in unemployment. Figure 1 confirms the commonly observed strong decrease in the aggregate hazard of leaving unemployment with elapsed duration in Britain during the first year in unemployment. This decline is not smooth since it is likely to be affected by the labour market programme Restart that is targeted at getting the unemployed back into work. The Restart programme consists of a compulsory interview after being unemployed for 6 months. The interview is designed to help the unemployed back into a job and make him less dependent on unemployment benefits. The employment office evaluates in detail the situation of the unemployed and provides job search advice and brings jobseekers in contact with employers or training agencies. This is likely to be the cause of the observed increase in the hazard of leaving unemployment after 6 months (Fig. 1). After the first interview the unemployed is in principle interviewed every 6 months. After (at most) 1 year a jobseeker moves to JSA (means tested) and also attends again a Restart interview. The treatment is rather heterogeneous, depending on the needs of the unemployed and the willingness of the unemployed to cooperate at an early stage. For instance, after 1 year many unemployed are more closely monitored and (have to) attend a so-called 1-2-1 programme that lasts for 6-12 weeks and is aimed at increasing the opportunities to find work. This may explain the increase in the hazard of leaving unemployment after the 12th month up to the 16th month (Fig. 1). Intensive counselling takes place again after 24 months and appropriate actions are then taken. This may explain the strong increase in the hazard of leaving unemployment. Of course, as in most studies, I cannot identify the causal effects of a labour market programme such as Restart on the hazard of leaving unemployment due to data limitations, but merely

${ }^{6}$ For additional descriptive statistics of the JUVOS sample I refer to Kalwij $(2001,2004)$. 

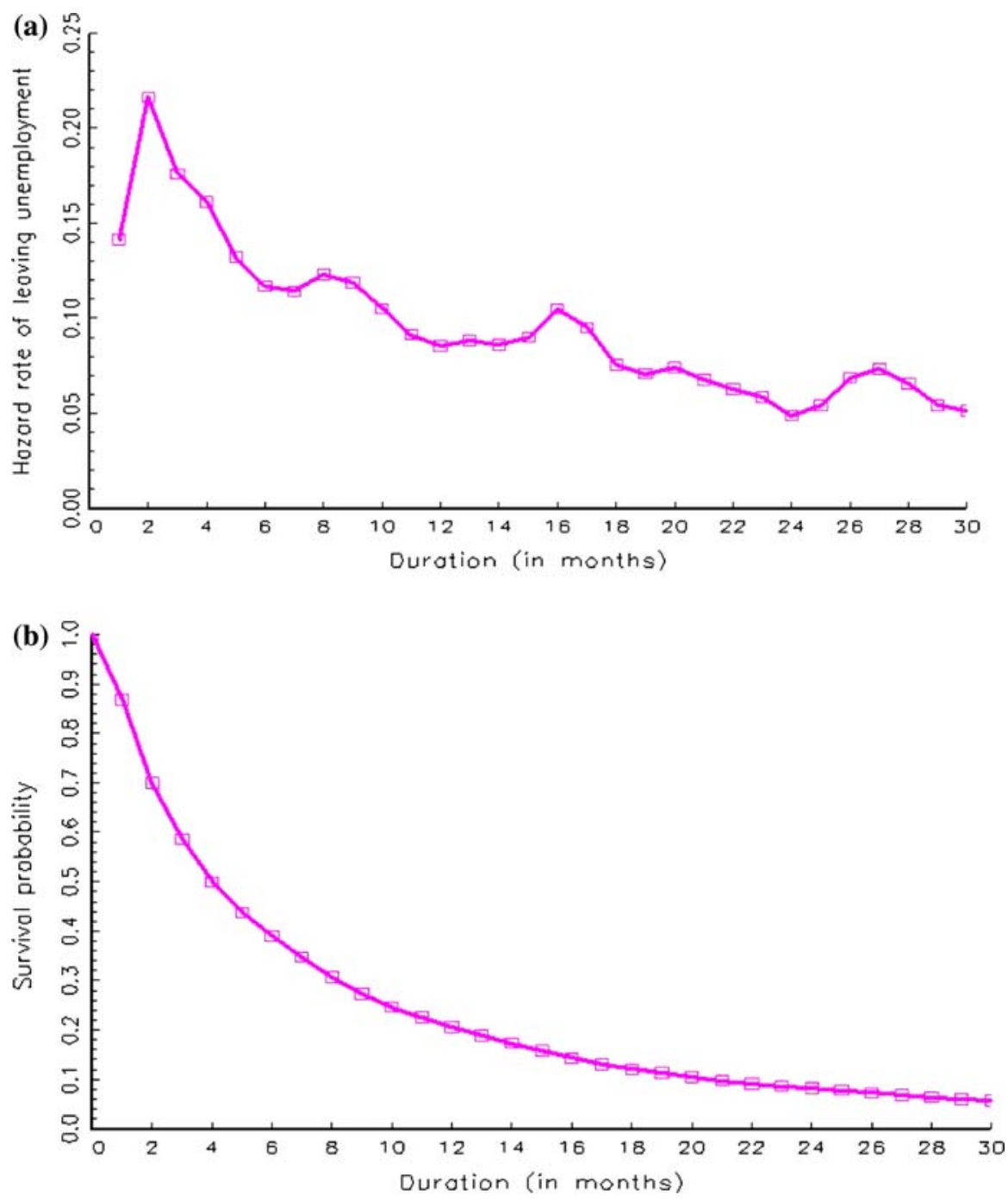

Fig. 1 The hazard rate of leaving unemployment within 1 month, as a function of the duration in unemployment, up to 30 months and the corresponding survival probability

point to plausible explanations of why the hazard rate is not smoothly declining with the duration in unemployment. The estimated survival function shows that $79.4 \%$ of unemployed men leave unemployment within 1 year and $5.7 \%$ are still unemployed after 30 months. Table 2 reports on the distribution of observations across the regions, marital status and age categories. The median unemployment duration is 4 months. The majority of observations are located in the South East, which is also the largest region by population size. Most unemployed are observed to be young and single.

I use the ratio of the stock of job vacancies over unemployment as indicator for the business cycle and refer to this as labour market tightness. The higher (lower) is this 
Table 2 Descriptive statistics of the covariates

\begin{tabular}{|c|c|c|c|}
\hline $\begin{array}{l}\text { labie } 2 \text { Descriptive statistics of } \\
\text { the covariates }\end{array}$ & & $\%$ of observations & $\begin{array}{l}\text { Median } \\
\text { duration } \\
\text { (in months) }\end{array}$ \\
\hline & \multicolumn{3}{|l|}{ Region } \\
\hline & South East (including London) & 28.0 & 4 \\
\hline & East Anglia & 3.1 & 3 \\
\hline & South West & 8.2 & 3 \\
\hline & West Midlands & 8.8 & 4 \\
\hline & East Midlands & 6.6 & 4 \\
\hline & Yorkshire and Humberside & 9.8 & 3 \\
\hline & North West & 12.3 & 4 \\
\hline & North & 6.9 & 4 \\
\hline & Wales & 5.6 & 4 \\
\hline & Scotland & 10.8 & 4 \\
\hline & All & 100.0 & 4 \\
\hline & \multicolumn{3}{|l|}{ Marital status } \\
\hline & Not single & 42.3 & 4 \\
\hline & Single & 57.7 & 4 \\
\hline & All & 100.0 & 4 \\
\hline & \multicolumn{3}{|c|}{ Age distribution at the start of the spell } \\
\hline & $18-20$ & 16.4 & 3 \\
\hline & $21-25$ & 24.1 & 3 \\
\hline & $26-30$ & 15.5 & 4 \\
\hline & $31-35$ & 11.2 & 4 \\
\hline & $36-40$ & 8.7 & 4 \\
\hline & $41-45$ & 7.5 & 4 \\
\hline Data: 84,388 men aged & $46-50$ & 6.5 & 4 \\
\hline April 1987 to September 1996 , & $51-55$ & 5.9 & 4 \\
\hline in total 222,901 spells of & $56-59$ & 4.1 & 4 \\
\hline unemployment and $5.8 \%$ of the & All & 100.0 & 4 \\
\hline
\end{tabular}

Data: 84,388 men aged 18-59years over the period April 1987 to September 1996, in total 222,901 spells of unemployment and $5.8 \%$ of the spells are incomplete

ratio the tighter (looser) is the labour market. The advantages of using this indicator are that I follow the theoretical work discussed in the introduction and on matching models (Pissarides 2000) and, from practical viewpoint, that this indicator can be constructed monthly on a regional level. Jackman and Layard (1991) and Turon (2003) also use this indicator. Vacancies are defined as vacancies at regional job centres and unemployment is defined as the regional claimant count. Figure 2 reports on this indicator per region and month over the observation period. Important is that the time span of the sample covers an entire business cycle. There may be underreporting of the number of vacancies as not all of them are registered at the regional job centres. The empirical analysis (partly) deals with this issue by only exploiting time variation for identification of the effects of the business cycle on unemployment duration. Regional specific dummy variables are included to control for possible differences in the effectiveness 


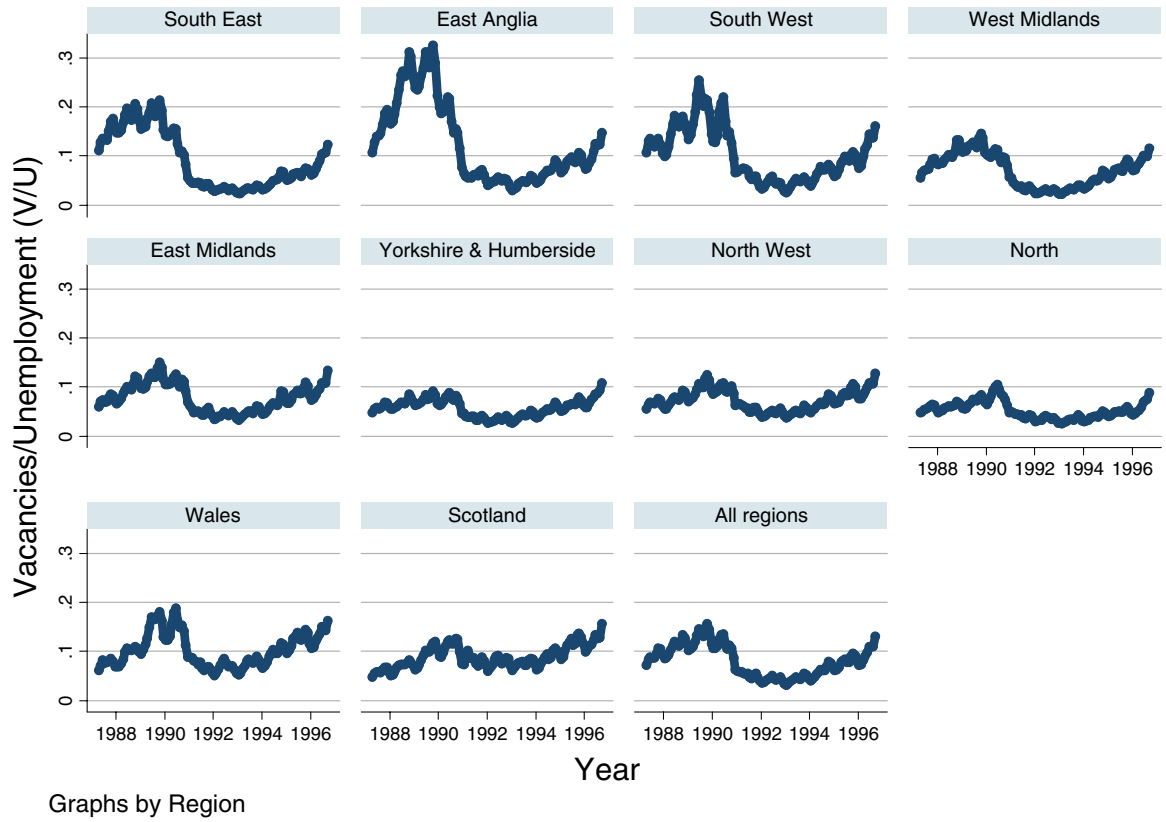

Fig. 2 Monthly regional vacancies over unemployment (labour market tightness) Source: National Statistics, http://www.statistics.gov.uk

of the regional job centres in gathering the information (see Sect. 3). Figure 2 shows considerable regional diversity in the variation over time in the indicator of labour market tightness.

\section{Econometric model and empirical specification}

Section 3.1 outlines the econometric model. Section 3.2 discusses the identification of the model and Sect.3.3 presents the empirical specification.

\subsection{The econometric model}

A multi-spell mixed proportional hazard rate model is used to model individuals' unemployment durations. The approach I take is considered to be a reduced-form approach and is taken in most of the empirical studies discussed in the introduction that analyse unemployment durations. Kalwij (2004) uses a similar econometric model for analyzing repeated unemployment of young British males. Lancaster (1990) and Van den Berg (2001) provide excellent overviews of the literature on the usage of these models and the linkage with the economic framework of job search theory.

The number of unemployment spells experienced by individual $i$ is denoted by $K_{i}$, the starting date of the $k$ th unemployment spell is denoted by $\tau_{i k}$, the duration of the $k$ th unemployment spell by $t_{i k}$ and $c_{i k}$ is a dummy variable equal to 1 if the $k$ th 
unemployment spell is incomplete (right-censored) and equal to 0 otherwise. $N$ denotes the number of individuals in the sample. $X_{i k}$ is a vector of observed individual characteristics and the unobserved individual specific characteristic is denoted by $v_{i}$. The (conditional) hazard rate of leaving unemployment is denoted by $h\left(t_{i k} \mid \tau_{i k}, X_{i k}, v_{i} ; \beta\right)$, where $\beta$ is a population parameter vector. The density function of the duration of unemployment is

$$
f\left(t_{i k} \mid \tau_{i k}, X_{i k}, v_{i} ; \beta\right)=h\left(t_{i k} \mid \tau_{i k}, X_{i k}, v_{i} ; \beta\right) \exp \left\{-\int_{0}^{t_{i k}} h\left(s \mid \tau_{i k}, X_{i k}, v_{i} ; \beta\right) d s\right\} .
$$

The survival function is given by

$$
1-F\left(t_{i k} \mid \tau_{i k}, X_{i k}, v_{i} ; \beta\right)=\exp \left\{-\int_{0}^{t_{i k}} h\left(s \mid \tau_{i k}, X_{i k}, v_{i} ; \beta\right) d s\right\} \text {. }
$$

The likelihood contribution for an incomplete spell is the survival function. For each individual the set of observations is denoted by $H_{i}=\left\{\tau_{i k}, t_{i k}, c_{i k}, X_{i k}\right\}_{k=1, \ldots, K_{i}}$. A support point approach as described in Heckman and Singer (1984) is used to model the distribution of the unobserved individual specific characteristic $v_{i}$. The number of mass points is denoted by $P$, a mass point is denoted by $v_{p}$, and the corresponding probability mass is given by $\operatorname{Pr}\left(v_{i}=v_{p}\right)=\pi_{p}$. I refer to Huh and Sickles (1994) for a discussion on the empirical implementation of this method and a comparison with alternative parametric approaches. Using the mass point distribution and Eqs. 1 and 2, the likelihood function for a sequence of unemployment spells of individual $i$ is

$$
L_{i}\left(H_{i} \mid \theta\right)=\sum_{p=1}^{P}\left(\prod_{k=1}^{K_{i}}\left[f\left(t_{i k} \mid \tau_{i k}, X_{i k}, v_{p} ; \beta\right)\right]^{1-c_{i k}}\left[1-F\left(t_{i k} \mid \tau_{i k}, X_{i k}, v_{p} ; \beta\right)\right]^{c_{i k}}\right) \pi_{p},
$$

where $\theta=\left(\beta, v_{1}, \ldots, v_{P}, \pi_{1}, \ldots, \pi_{P}\right)$. The maximum likelihood estimates are given by

$$
\hat{\theta}=\underset{\theta}{\arg \max } \sum_{i=1, \ldots, N} \ln \left(L_{i}\left(H_{i} \mid \theta\right)\right)
$$

\subsection{Model identification}

The identification of a single spell duration model with duration dependence and a distribution of unobserved heterogeneity is achieved by making a proportionality assumption and an assumption concerning either the first moment or the tail behaviour of the mixing distribution (Elbers and Ridder 1982). In practice, however, identification 
based on these assumptions may turn out to be problematic (Baker and Melino 2000). The data I use for estimating the model presented above contain multiple unemployment spells for many individuals (multi-spell data). This panel aspect of the data is very important for the identification of the model outlined above. In particular it is important for the identification of the interactions between labour market tightness (the business cycle indicator) and individual duration dependence. Honoré (1993) shows that identification of a multi-spell mixed proportional hazard model is achieved under much weaker assumptions than a single-spell mixed proportional hazard model and, most importantly, he shows that with a fixed heterogeneity distribution over spells it is not necessary to make any assumptions about the mixing distribution. Van den Berg (2001) provides an excellent overview of identification issues when using multi-spell duration data. Important for this paper is that when using multi-spell data the identification of the model outlined above requires that the unobserved individual specific characteristic $\left(v_{i}\right)$ is constant across spells and requires proportionality between the unobserved individual heterogeneity term $\left(v_{i}\right)$ and the duration effect. Identification of the model does not require that there are observed explanatory variables and as a result the distribution of $v_{i}$ is conditional on $X_{i k}$. A further important advantage is that the model does not require proportionality between the observed explanatory variables and individual duration dependence. This means that interactions between labour market tightness and the duration in unemployment are allowed for.

The theoretical results discussed above on the identification of a multi-spell mixed proportional hazard model require at least two completed spells of unemployment for each individual (Van den Berg 2001). However, for $40 \%$ of the individuals in the data I observe only one complete or incomplete spell of unemployment (see Table 1). To provide insights in the empirical importance of this for model identification, the empirical analysis has been repeated for a selective sample of individuals with at least two completed spells of unemployment (see Table 5). The empirical results changed only marginally and did not alter the main conclusions of this paper. For this reason, and to avoid any selectivity biases, I use the whole sample, including individuals with only one spell of unemployment, when estimating the model outlined in this section.

\subsection{The empirical specification}

The empirical hazard rate function of leaving unemployment is formalized as follows

$$
\begin{aligned}
\ln \left(h\left(s \mid \tau_{i k}, X_{i k}, v_{i} ; \beta\right)\right)= & \psi_{1}\left(s \mid \beta_{1}\right)+\psi_{2}\left(s \mid \tau_{i k} ; \beta_{2}\right) \\
& +\psi_{3}\left(s \mid X_{i k} ; \beta_{3}\right)+\psi_{4}\left(\tau_{i k}, v_{i} ; \beta_{4}\right) .
\end{aligned}
$$

The (elapsed) duration in unemployment is denoted by $s$. The first term in the r.h.s. (right hand side) is the effect of the duration in unemployment on the hazard of leaving unemployment, i.e. individual duration dependence, the second term is the effect of the state of the business cycle at calendar time $\left(\tau_{i k}+s\right)$ on the hazard and on individual duration dependence, the third term is the effect of observed (time varying) individual heterogeneity on the hazard and the fourth term controls for unobserved individual heterogeneity $\left(v_{i}\right)$. Inflow heterogeneity, i.e. the variation over the business 
cycle in the (unobserved) composition of the newly unemployed, is modelled as a shift in the mean of the distribution of unobserved individual heterogeneity. Below I discuss the specification of these four terms in more detail.

The empirical specifications of the first four terms in the r.h.s. of Eq. 5 are as follows. Individual duration dependence is parameterised using monthly dummy variables

$$
\psi_{1}\left(s \mid \beta_{1}\right)=\beta_{1,1}+\sum_{d=2}^{30} \beta_{1, d} I(s=d)+\beta_{1,31} I(s \geq 31)+\beta_{1,32} I(s \geq 31) \ln (s)
$$

$I($.$) is an indicator function equal to one if the argument is true and equal to zero$ otherwise. The parameters $\beta_{1,2}, \ldots, \beta_{1,32}$ determine the pattern of individual duration dependence in the baseline situation. I use a flexible specification up to and including the 30th month. From the 31st month onwards individual duration dependence is modelled using the logarithm of duration. About $3 \%$ of the completed spells in the sample have a duration exceeding 30 months. $^{7}$

The business cycle is allowed to affect the hazard of leaving unemployment, individual duration dependence, and the composition of the newly unemployed (second and fourth terms in the r.h.s. of Eq. 5). I refer to Imbens (1994) for a discussion on the identification of duration and calendar time effects. The effects of the business cycle on the hazard of leaving unemployment are identified without making an additional assumption, given the available data, but to also identify inflow heterogeneity, together with a flexible individual duration dependence specification, demands an identifying assumption. This is because duration is always equal to the time of entering minus the time of leaving unemployment. Following the studies discussed in the introduction that use individual-level data, these time effects are identified by using a business cycle indicator. ${ }^{8}$ As is discussed in Sect. 2, I use the logarithm of monthly regional labour market tightness, defined as the number of vacancies over unemployment, as an indicator for the business cycle [denoted by $\ln (V U)$ ]

$$
\begin{aligned}
\psi_{2}\left(s \mid \tau_{i k} ; \beta_{2}\right)= & \beta_{2,1} \ln \left(V U_{\tau_{i k+s}}\right)+\sum_{d=2}^{30} \beta_{2, d} I(s=d) \ln \left(V U_{\tau_{i k+s}}\right) \\
& +\beta_{2,31} I(s \geq 31) \ln \left(V U_{\tau_{i k}+s}\right)+\beta_{2,32} I(s \geq 31) \ln (s) \ln \left(V U_{\tau_{i k+s}}\right) \\
& +\sum_{m=2}^{12} \beta_{2,31+m} I\left(M_{\tau_{i k+s}}=m\right)
\end{aligned}
$$

$\beta_{2,1}$ is the effect of the business cycle on the hazard of leaving unemployment, and the parameters $\beta_{2,2}, \ldots, \beta_{2,32}$ determine the variation in individual duration dependence over the business cycle. Testing whether or not individual duration dependence varies over the business cycle amounts to testing the hypothesis $H_{0}: \beta_{2,2}=\cdots=\beta_{2,32}=0$.

\footnotetext{
7 Censoring the data at 30 months does not change the main conclusions of this paper.

8 In an earlier version I included year dummy variables in the hazard of leaving unemployment. This did not affect the main results of the paper. To keep the results transparent I omit these and only control for time effects through labour market tightness (the business cycle indicator).
} 
The last term in the r.h.s. of Eq. 7 includes the seasonal effects in the hazard of leaving unemployment and the parameters $\beta_{2,33}, \ldots, \beta_{2,43}$ denote the effects for, respectively, February to December, with January as reference month and where $M$ denotes the month of leaving unemployment. The observed covariates are modelled as follows

$$
\begin{aligned}
\psi_{3}\left(s \mid X_{i k} ; \beta_{3}\right)= & \beta_{3,1} \operatorname{Single}_{i k}+\sum_{r=2}^{10} \beta_{3, r} I\left(\text { region }_{i k}=r\right) \\
& +\sum_{a=2}^{9} \beta_{3,9+a} I\left(\operatorname{agegr}_{i k}(s)=a\right) .
\end{aligned}
$$

The covariate single is a dummy variable equal to one if the individual is single at the beginning of the unemployment spell, and zero otherwise. The covariate region is the region in which the Employment Office is located where the individual is registered. Ten regions are distinguished and the reference region is 'South East' (see Sect. 2). The time-varying covariate agegr $(s)$ is the age group of the individual at elapsed duration $s .{ }^{9}$ I distinguish nine age groups: $18-20,21-25,26-30,31-35,36-40,41-45,46-50$, 51-55 and 56-59 years. The reference age group is $18-20$ years.

As discussed above, identification of the model requires unobserved individual heterogeneity $\left(v_{i}\right)$ to enter the log-hazard rate additively. Therefore, in line with Turon (2003), inflow heterogeneity is modelled by allowing the mean of the distribution of the unobserved individual specific characteristic $\left(v_{i}\right)$ to shift with (the logarithm of) labour market tightness and the month at the time of entering unemployment. This is formalized by allowing the hazard of leaving unemployment to depend on labour market tightness and the calendar month at the time of entering unemployment $\left(\tau_{i k}\right)$, with January as the reference month,

$$
\psi_{4}\left(\tau_{i k}, v_{i} ; \beta_{4}\right)=\beta_{4.1} \ln \left(V U_{\tau_{i k}}\right)+\sum_{m=2}^{12} \beta_{4, m} I\left(M_{\tau_{i k}}=m\right)+v_{i}
$$

\section{Empirical results}

Section 4.1 presents the estimation results. Section 4.2 discusses in more detail individual duration dependence over the business cycle and Sect. 4.3 presents a sensitivity analysis and compares the results with the findings of previous studies.

The estimation results of the complete model as outlined in Sect. 3 are reported in the Appendix. To facilitate the discussion I summarize the empirical results in Figs. 3, 4, 5 and Table 3 for a reference individual and evaluate business cycle effects at three states: a relatively tight and loose labour market and the baseline situation where labour market tightness is at its regional average. A loose labour market refers to the 10th percentile, the baseline situation to the 50th percentile and a tight labour

\footnotetext{
9 Including the age category at the start of the spell as a time-constant covariate [instead of agegr ${ }_{i k}(s)$ ] does not affect the main results and conclusions.
} 

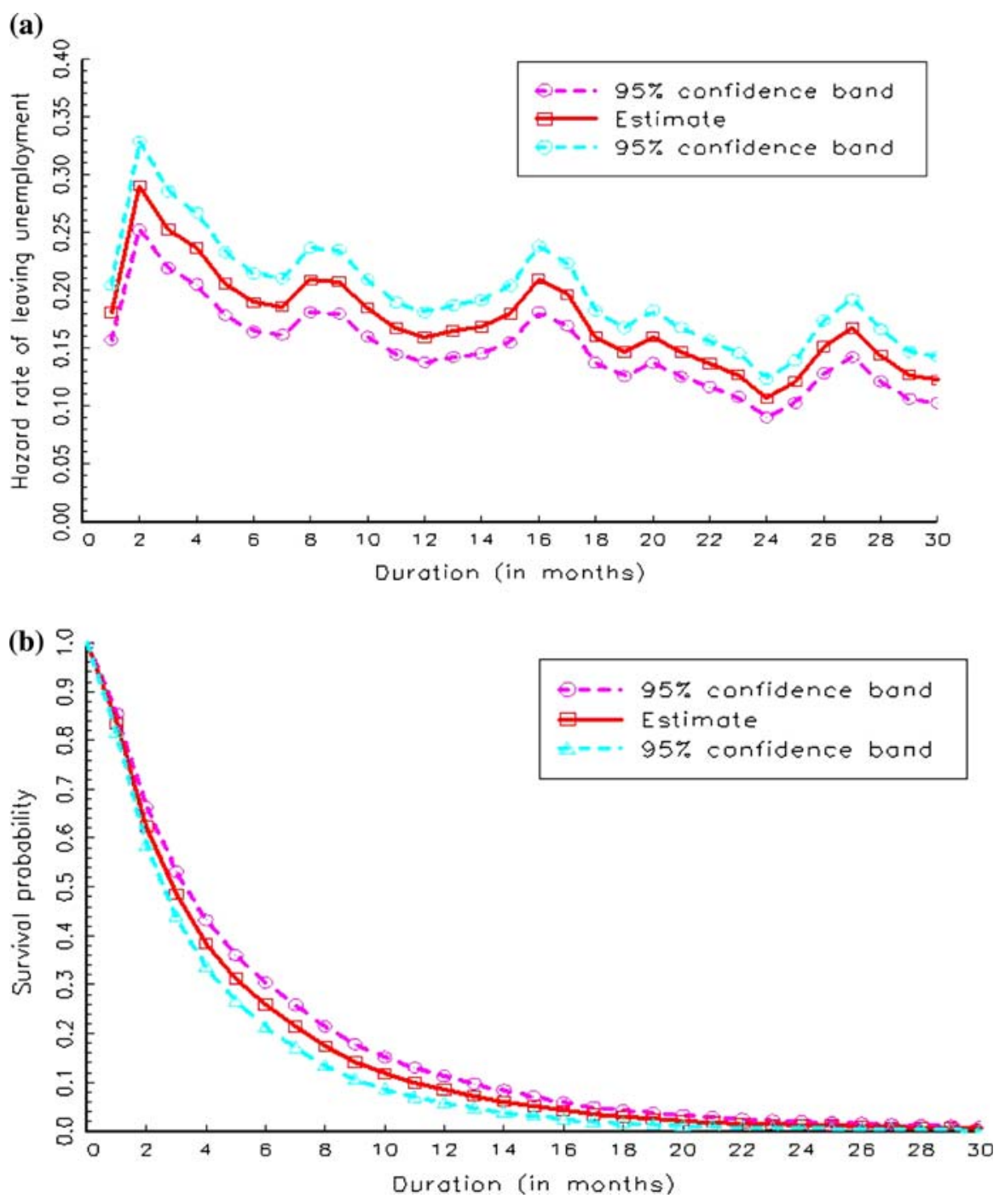

Fig. 3 Estimated hazard of leaving unemployment as a function of the duration in unemployment and the corresponding survivor function for a reference individual

market to the 90th percentile of the empirical distribution of labour market tightness. I choose as baseline case, or reference individual, an 18 to 20 years old single man, who became unemployed in January, is in his first month of unemployment, registered at an employment office in the South East and his unobserved characteristic is of type $2\left(v_{2}\right)$. The reference individual in the baseline situation has a hazard rate of leaving unemployment equal to 0.18 and this baseline value is set equal to $100 \%$ in Table 3 . Thus the percentages reported in Table 3 are percentages of the baseline hazard and because a proportional hazard specification is used the effect on the baseline hazard of any combination of characteristics is a combination of the corresponding percentages. 


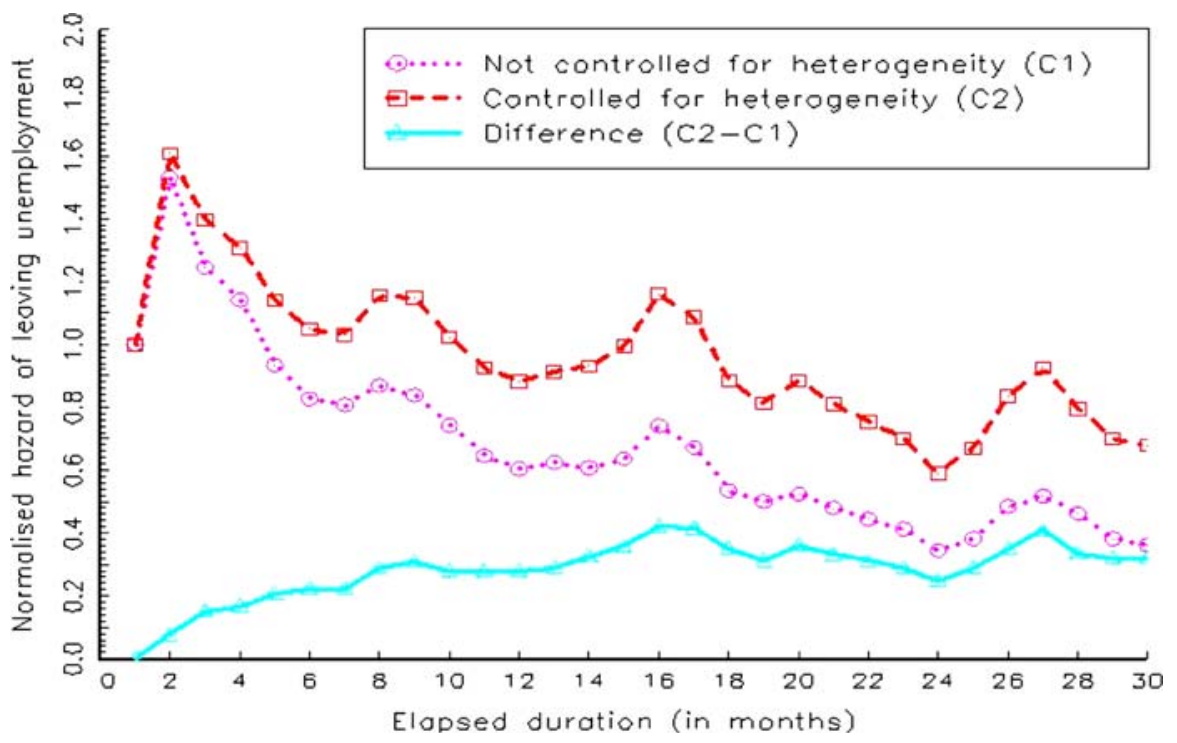

Fig. 4 Duration dependence with and without controlling for individual heterogeneity. The hazard rate of leaving unemployment in the first month is normalised to 1

\subsection{Estimation results}

Figure 3a shows that the hazard of leaving unemployment increases sharply from the first to the second month in unemployment and decreases thereafter with elapsed duration. The hazard of leaving unemployment in the 12 th month is $88 \%$ of that of the hazard in the first month and 55\% of the hazard in the second month. Figure $3 \mathrm{~b}$ shows that a reference individual has about a $90 \%$ probability of leaving unemployment within 1 year.

Table 3, first part, reports on the business cycle effects on individuals' hazard of leaving unemployment. Table 3 (top, first column) shows that an individual's hazard of leaving unemployment increases strongly with labour market tightness. The baseline hazard of leaving unemployment is almost $80 \%$ higher in a tight than in a loose labour market (134.1 vs. 74.6). The most notable seasonal variation in the hazard of leaving unemployment is the relatively low hazards in November and December. Table 3 (top, last columns) reports on the effect of labour market tightness on (unobserved) inflow heterogeneity with respect to the hazard of leaving unemployment and shows that men who become unemployed when the labour market is tight have on average a $21 \%$ lower hazard of leaving unemployment than men who become unemployed when the labour market is loose. Seasonal differences in the composition of the newly unemployed with respect to the hazard of leaving unemployment are relatively small.

Table 3, second half, reports on the effects of individual heterogeneity on the hazard of leaving unemployment. The age effects show a rapid decrease in the hazard with age for the young unemployed and a relatively constant hazard from the mid 30's onwards. Regional differences in the hazard of leaving unemployment are relatively 
(a)

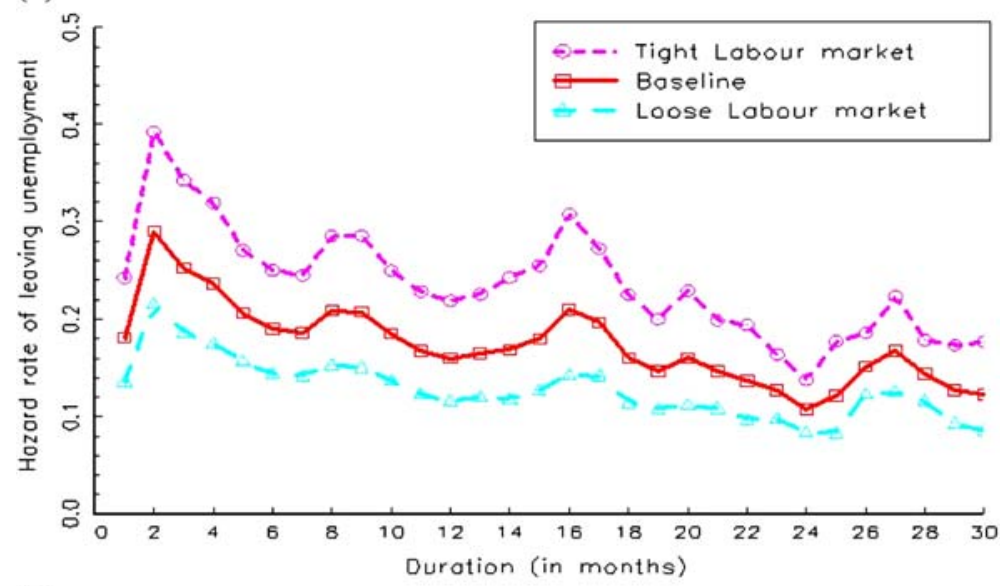

(b)
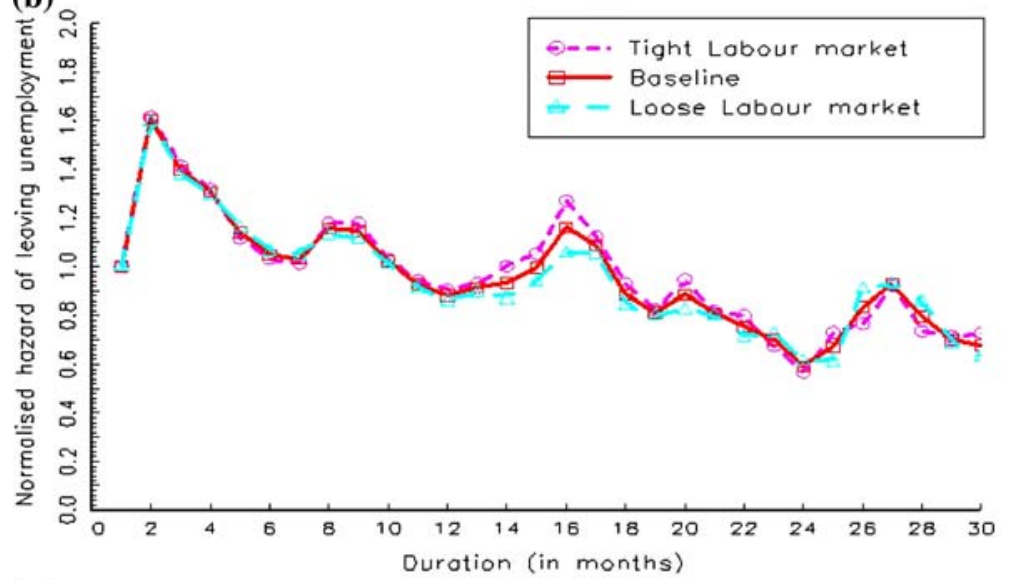

(c)

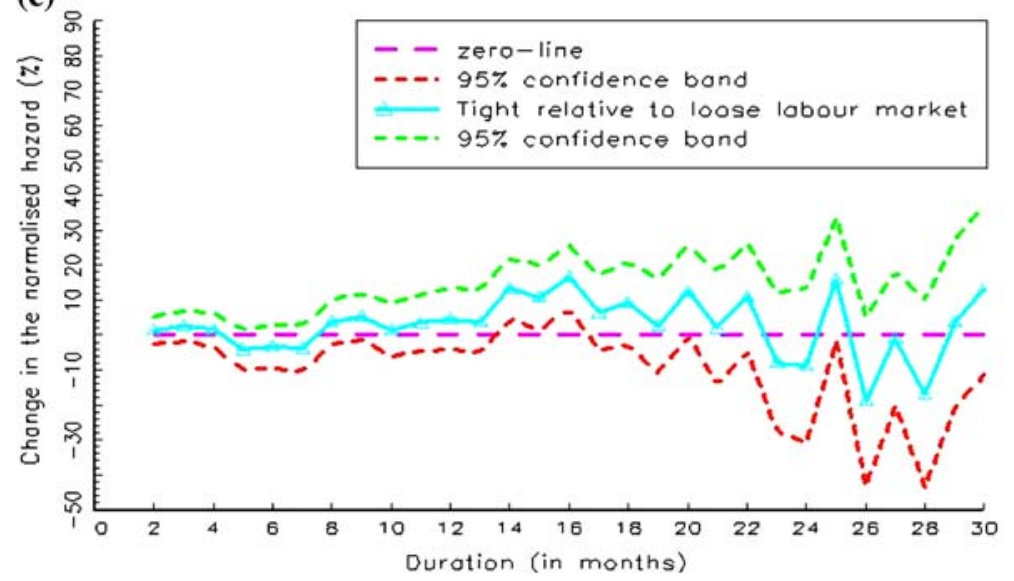

Fig. 5 Individual duration dependence over the business cycle 
Table 3 The empirical results

\begin{tabular}{|c|c|c|c|c|c|}
\hline Time of leaving unemployment & Estimate & SE & Time of entering unemployment & Estimate & SE \\
\hline Business cycle ${ }^{a}$ & & & Business cycle ${ }^{a}$ & & \\
\hline Tight labour market & 134.1 & 1.38 & Tight labour market & 88.7 & 0.64 \\
\hline Baseline* & 100.0 & - & Baseline* & 100.0 & - \\
\hline Loose labour market & 74.6 & 0.76 & Loose labour market & 112.8 & 0.81 \\
\hline Season & & & Season & & \\
\hline January* & 100.0 & - & January* & 100.0 & - \\
\hline February & 83.0 & 0.97 & February & 102.2 & 1.36 \\
\hline March & 77.2 & 0.91 & March & 98.9 & 1.34 \\
\hline April & 96.7 & 1.11 & April & 102.6 & 1.32 \\
\hline May & 77.2 & 0.94 & May & 105.0 & 1.44 \\
\hline June & 72.4 & 0.89 & June & 108.3 & 1.43 \\
\hline July & 89.7 & 1.04 & July & 106.6 & 1.34 \\
\hline August & 77.7 & 0.93 & August & 100.9 & 1.36 \\
\hline September & 96.1 & 1.11 & September & 100.6 & 1.37 \\
\hline October & 89.1 & 1.08 & October & 109.5 & 1.45 \\
\hline November & 59.0 & 0.76 & November & 110.4 & 1.49 \\
\hline December & 54.5 & 0.7 & December & 111.7 & 1.44 \\
\hline \multicolumn{6}{|l|}{ Age category (in years) } \\
\hline $18-20 *$ & 100.0 & - & & & \\
\hline $21-25$ & 96.1 & 0.87 & & & \\
\hline $26-30$ & 83.3 & 0.86 & & & \\
\hline $31-35$ & 79.2 & 0.93 & & & \\
\hline $36-40$ & 74.4 & 0.94 & & & \\
\hline $41-45$ & 74.5 & 0.99 & & & \\
\hline $46-50$ & 73.4 & 1.02 & & & \\
\hline $51-55$ & 67.9 & 0.97 & & & \\
\hline $56-59$ & 70.7 & 1.19 & & & \\
\hline \multicolumn{6}{|l|}{ Region } \\
\hline South East* & 100.0 & - & & & \\
\hline East Anglia & 117.4 & 1.95 & & & \\
\hline South West & 109.6 & 1.26 & & & \\
\hline West Midlands & 95.6 & 1.04 & & & \\
\hline East Midlands & 102.2 & 1.29 & & & \\
\hline Yorkshire and Humberside & 102.4 & 1.06 & & & \\
\hline North West & 96.9 & 0.95 & & & \\
\hline North & 98.1 & 1.16 & & & \\
\hline Wales & 100.5 & 1.35 & & & \\
\hline Scotland & 100.6 & 1.04 & & & \\
\hline \multicolumn{6}{|l|}{ Marital Status } \\
\hline Married & 116.7 & 3.38 & & & \\
\hline Single* & 100.0 & - & & & \\
\hline
\end{tabular}


Table 3 continued

\begin{tabular}{lcllll}
\hline Time of leaving unemployment & Estimate & SE & Time of entering unemployment & Estimate & SE \\
\hline & \multicolumn{4}{l}{ The distribution of unobserved individual heterogeneity } \\
& Estimate & SE & Probability estimate & SE \\
\hline Support point $v_{1}$ & 53.1 & 2.54 & 0.36 & 0.030 \\
Support point $v_{2}{ }^{*}$ & 100.0 & - & 0.40 & 0.041 \\
Support point $v_{3}$ & 156.5 & 5.29 & 0.23 & 0.057 \\
Support point $v_{4}$ & 277.0 & 19.64 & 0.01 & 0.004 \\
\hline
\end{tabular}

Each cell contains the effect on the baseline hazard of leaving unemployment relative to the baseline hazard of leaving unemployment (set equal to 100\%). The asterisks show the characteristics of the baseline hazard $S E$ standard error

a A loose labour market refers to the 10th percentile, the baseline situation to the 50th percentile and a tight labour market to the 90th percentile of the empirical distribution of labour market tightness

small. ${ }^{10}$ Singles have a $17 \%$ lower hazard of leaving unemployment compared to married men. The distribution of unobserved heterogeneity is reported at the bottom of Table 3. Individuals with an unobserved characteristic corresponding to the third support point have a three times higher hazard of leaving unemployment compared to individuals with an unobserved characteristic corresponding to the first support point (156.5 vs. $53.1 \%$ ). In contrast to the relatively small effects of observed individual heterogeneity, unobserved individual heterogeneity plays an important role in explaining the hazard of leaving unemployment. Figure 4 shows that sorting, that is caused by significant individual heterogeneity, plays an important role in explaining the observed (aggregate) negative duration dependence. The decrease in the hazard of leaving unemployment between the 1st and 24th month in unemployment is about $41 \%$ with and $66 \%$ without controlling for individual heterogeneity. The different of $25 \%$-points implies that sorting accounts for just over one-third of the strong decrease in the hazard of leaving unemployment with duration. Negative individual duration dependence explains the remaining two-thirds of this strong decrease.

\subsection{Individual duration dependence over the business cycle}

Figure 5a shows the hazard of leaving unemployment, as a function of the duration in unemployment, for three states of the business cycle. At all durations the hazard of leaving unemployment is significantly higher in a tight than in a loose labour market. To examine how individual duration dependence changes over the business cycle I normalise the hazard in the first month in unemployment to one (Fig. 5b). Standard errors for all durations up to 30 months on the differences in the normalised hazards in a tight relatively to a loose labour market are shown in Fig. 5c. As discussed in the introduction, the matching model of Lockwood (1991) predicts that the long term unemployed benefit relatively less from a tightening of the labour

\footnotetext{
10 See Kalwij (2004) for a more detailed analysis of regional differences in not only the hazard of leaving unemployment but also, and more importantly, in the hazard of (re-) entering unemployment.
} 
market (suggests a negative slope in Fig. 5c), and the ranking model of Blanchard and Diamond (1994) predicts that the long term unemployed benefit relatively more from a tightening of the labour market (suggests a positive slope in Fig. 5c). A formal test rejects the null-hypothesis that individual duration dependence does not vary over the business cycle. ${ }^{11}$ This rejection is primarily due to significant effects for the durations 14-16 months. These effects are relatively small compared to the overall effect of the business cycle; at most a $16.7 \%$ increase with a standard error of $4.6 \%$. The conclusion that emerges from Fig. $5 \mathrm{a}-\mathrm{c}$ is that individual duration dependence does not change in a systematic way over the business cycle. Hence, no strong empirical evidence is found in favour of the matching model of Lockwood (1991) or the ranking model of Blanchard and Diamond (1994). It may of course be the case that the opposite effects concerning the cyclical sensitivity of duration dependence in the studies of Blanchard and Diamond (1994) and Lockwood (1991) neutralize each other.

\subsection{Sensitivity analysis}

The conclusion that individual duration dependence does not vary in a systematic way over the business cycle is in contrast with the conclusions of several of the previous empirical studies mentioned in the introduction. I am therefore interested in the conclusion one would draw when using the restrictive models of empirical studies that reach a different conclusion. For this reason I estimate the model without controlling for individual heterogeneity (both observed and unobserved heterogeneity) and inflow heterogeneity (i.e. the variation over the business cycle in the composition of the newly unemployed). These results are shown in Fig. 6a-c and for these restricted models I only report on the differences in the normalised hazards for all durations between the situations of a tight and a loose labour market. A cautionary note on the interpretation of the results discussed below is that many previous empirical studies did not only use a different empirical model but also analysed different countries. ${ }^{12}$ Figure 6 a is based on a model that does not control for individual heterogeneity and inflow heterogeneity. Figure 6a shows that aggregate duration dependence is stronger the tighter the labour market at short durations and weaker the tighter the labour market at long durations. This is in line with the conclusion of Abbring et al. (2001) who do not fully control for inflow heterogeneity and use aggregate US data. Figure $6 \mathrm{~b}$ is based on a model that controls for inflow heterogeneity but not for individual heterogeneity. The most striking results in Fig. $6 \mathrm{~b}$ is that once controlled for inflow heterogeneity the apparent upward sloping difference in Fig. 6a has virtually disappeared. This finding that individual duration dependence does not significantly vary over the business cycle at higher durations once controlled for inflow heterogeneity is in line with the evidence for British men in Turon (2003). She uses aggregate data and does not identify significant presence of unobserved individual heterogeneity. The significant cyclical variation present in Fig. $6 \mathrm{~b}$ at short durations is reported in

\footnotetext{
${ }^{11} H_{0}: \beta_{2,2}=\cdots=\beta_{2,32}=0$ The Wald-test statistic is equal to 81.5 and the critical value is 45 with a $5 \%$ level of significance.

${ }^{12}$ For instance, the different results obtained for other countries may be due to differences in labour market institutions.
} 

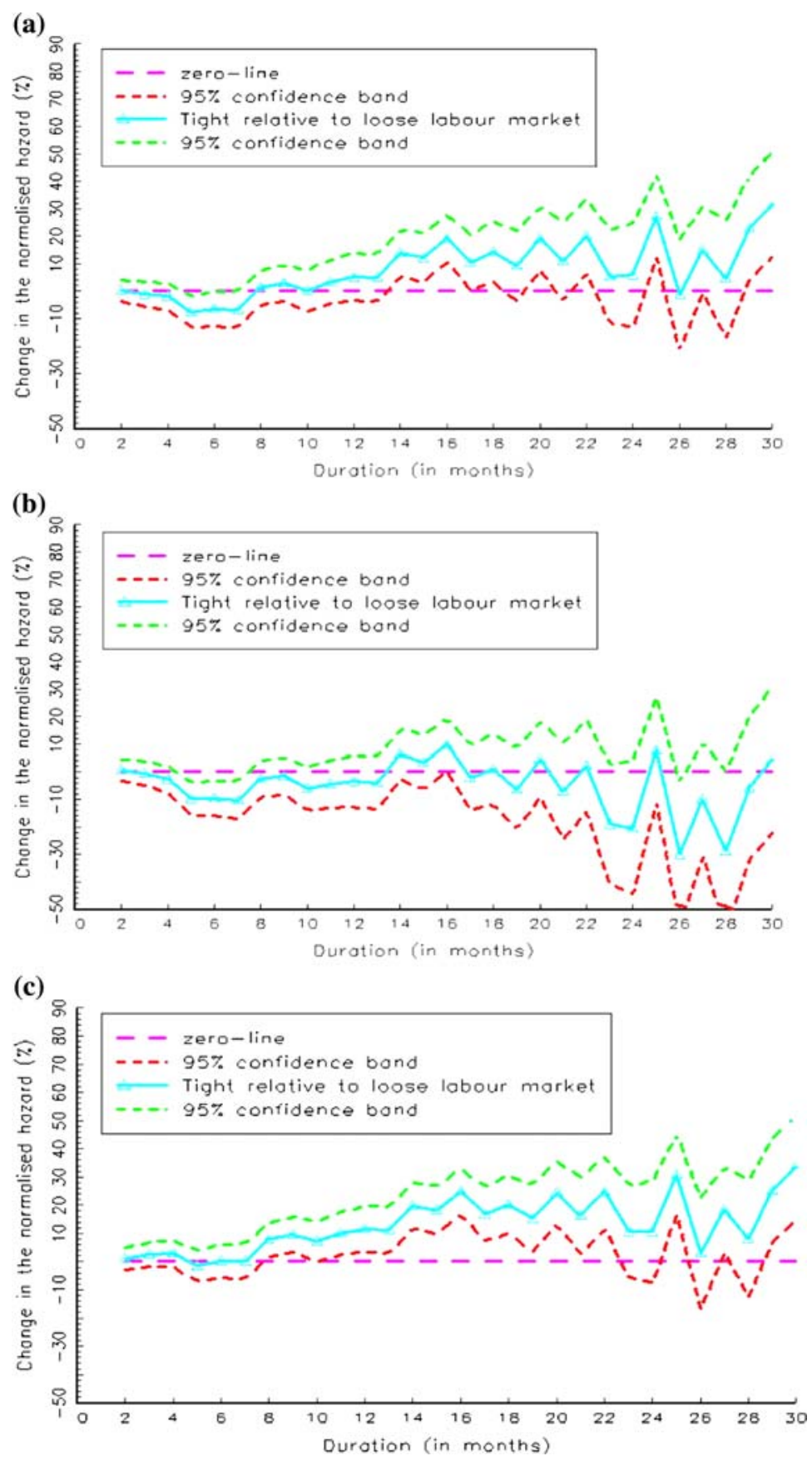

Fig. 6 Sensitivity analysis. Differences over the business cycle in the normalised hazards by duration using three restricted models: a without controlling for individual heterogeneity and inflow heterogeneity, b without controlling for individual heterogeneity and controlling for inflow heterogeneity, and c controlling for individual heterogeneity and not controlling for inflow heterogeneity 
several studies, for instance in Rosholm (2001), and may be due to insufficient control for unobserved individual heterogeneity. Figure $6 \mathrm{c}$ is based on a model that controls for individual heterogeneity but not for inflow heterogeneity. Figure $6 \mathrm{c}$ clearly shows that individual duration dependence is weaker the tighter the labour market and that these differences are significant for most durations from the eighth month onwards. The pattern in Fig. $6 \mathrm{c}$ is in line with the prediction of the ranking model of Blanchard and Diamond (1994). For instance, Dynarski and Sheffrin (1990), using US individual level panel data, control for heterogeneity but not for inflow heterogeneity and this may explain their conclusion, in line with Fig. 6c, that the business cycle has the strongest effect on the longest elapsed durations in unemployment.

The results of this sensitivity analysis show that duration dependence on an aggregate level is stronger the tighter the labour market at short durations and weaker the tighter the labour market at long durations (Fig. 6a) but that most of this variation is explained by individual heterogeneity. Ignoring individual heterogeneity biases the pattern of duration dependence somewhat in favour of cyclical sensitivity at shorter durations (Fig. 6b vs. Fig. 5c). Moreover, when ignoring that the composition of the newly unemployed varies over the business cycle (i.e. inflow heterogeneity) one can mistakenly conclude that there is significant empirical evidence of negative individual duration dependence being weaker the tighter the labour market, as predicted by the ranking model of Blanchard and Diamond (1994) (Fig. 6c vs. Fig. 5c). A possible explanation for this latter finding is given by counter-cyclical inflow heterogeneity and a pro-cyclical individual hazard of leaving unemployment. The looser the labour market the higher skilled the average newly unemployed and all unemployed individuals remain unemployed longer. When the labour market tightens the pool of unemployed at each duration is relatively higher skilled compared to a situation when the labour market loosens, hence relatively higher (normalised) hazards of leaving unemployment. These dynamics are in line with the pattern in Fig. 6c. This explanation is empirically supported by the fact I find counter-cyclical inflow heterogeneity and that once controlled for inflow heterogeneity the upward slope in Fig. 6c virtually disappears (Fig. 5c).

\section{Summary}

In this paper I examined the effects on the hazard of leaving unemployment of the duration in unemployment, individual heterogeneity and the business cycle. And in particular I examined in detail the variation over the business cycle in individual duration dependence of the hazard of leaving unemployment. For this purpose I have used a large panel of administrative unemployment records of British males from April 1987 to September 1996 and the ratio regional vacancies over unemployment, referred to as labour market tightness, to control for business cycle effects. The main empirical findings are the following:

(1) The strong decrease in the aggregate hazard of leaving unemployment with elapsed duration is about $65 \%$ within the first 2 years. Sorting, due to individual heterogeneity, accounts for one-third and negative individual duration dependence for two-thirds of this decrease. 
(2) Significant and strong business cycle effects are identified. An individual's hazard of leaving unemployment is about $80 \%$ higher in a tight relative to a loose labour market. Concerning the variation over the business cycle in the composition of the newly unemployed with respect to their employability (inflow heterogeneity) I find that men who become unemployed when the labour market is tight have on average a $21 \%$ lower hazard of leaving unemployment than men who become unemployed when the labour market is loose. The pro-cyclical effect of the business cycle on the individual hazard of leaving unemployment dominates the counter-cyclical effect of the business cycle on the hazard through inflow heterogeneity. This leaves the business cycle effect on individuals' hazard of leaving unemployment as the main determinant of the longer average unemployment durations in a loose labour market. The results imply, by combining these effects, that the average hazard of leaving unemployment is about $35 \%$ higher in a tight than in a loose labour market.

(3) Most of the systematic variation over the business cycle in duration dependence of the hazard of leaving unemployment on an aggregate level is explained by individual heterogeneity, and in particular inflow heterogeneity. Individual duration dependence does not vary over the business cycle in a way that would lend support to the predictions concerning this of the matching model of Lockwood (1991) or the ranking model of Blanchard and Diamond (1994). Moreover I show that failing to control for inflow heterogeneity, as is often done in empirical research, biases the variation in duration dependence over the business cycle in favour of the prediction concerning this variation of the ranking model of Blanchard and Diamond (1994).

Acknowledgments I wish to thank the seminar participants at the Departments of Economics at the Universities of Amsterdam, Oxford, Reading and Tilburg, Mary Gregory at the University of Oxford, and three anonymous referees for helpful comments and suggestions. I thank Nigel Stuttard at National Statistics for providing the JUVOS data. Financial support from the Leverhulme Trust project 'The labour market consequences of technical and structural change' is gratefully acknowledged.

Open Access This article is distributed under the terms of the Creative Commons Attribution Noncommercial License which permits any noncommercial use, distribution, and reproduction in any medium, provided the original author(s) and source are credited.

\section{Appendix}

See Tables 4 and 5.

Table 4 Estimation results of the complete model outlined by Eqs. 5-9

\begin{tabular}{|c|c|c|c|c|c|c|c|c|}
\hline \multicolumn{3}{|c|}{ Duration dependence } & \multicolumn{3}{|c|}{$\begin{array}{l}\text { Duration dependence } \\
\times \text { labour market tightness }\end{array}$} & \multicolumn{3}{|c|}{$\begin{array}{l}\text { Seasonal effects } \\
\text { (months of the year) }\end{array}$} \\
\hline Parameter & Estimate & SE & Parameter & Estimate & SE & Parameter & Estimate & SE \\
\hline$\beta_{1,1}$ & -2.190 & 0.029 & $\beta_{2,1}$ & 0.489 & 0.017 & $\beta_{2,33}$ & -0.186 & 0.012 \\
\hline$\beta_{1,2}$ & 0.474 & 0.008 & $\beta_{2,2}$ & 0.011 & 0.017 & $\beta_{2,34}$ & -0.259 & 0.012 \\
\hline
\end{tabular}


Table 4 continued

\begin{tabular}{|c|c|c|c|c|c|c|c|c|}
\hline \multicolumn{3}{|c|}{ Duration dependence } & \multicolumn{3}{|c|}{$\begin{array}{l}\text { Duration dependence } \\
\times \text { labour market tightness }\end{array}$} & \multicolumn{3}{|c|}{$\begin{array}{l}\text { Seasonal effects } \\
\text { (months of the year) }\end{array}$} \\
\hline Parameter & Estimate & SE & Parameter & Estimate & SE & Parameter & Estimate & SE \\
\hline$\beta_{1,3}$ & 0.334 & 0.010 & $\beta_{2,3}$ & 0.021 & 0.019 & $\beta_{2,35}$ & -0.034 & 0.011 \\
\hline$\beta_{1,4}$ & 0.268 & 0.010 & $\beta_{2,4}$ & 0.013 & 0.021 & $\beta_{2,36}$ & -0.259 & 0.012 \\
\hline$\beta_{1,5}$ & 0.130 & 0.012 & $\beta_{2,5}$ & -0.035 & 0.023 & $\beta_{2,37}$ & -0.323 & 0.012 \\
\hline$\beta_{1,6}$ & 0.047 & 0.013 & $\beta_{2,6}$ & -0.027 & 0.025 & $\beta_{2,38}$ & -0.109 & 0.012 \\
\hline$\beta_{1,7}$ & 0.029 & 0.014 & $\beta_{2,7}$ & -0.031 & 0.027 & $\beta_{2,39}$ & -0.252 & 0.012 \\
\hline$\beta_{1,8}$ & 0.144 & 0.014 & $\beta_{2,8}$ & 0.033 & 0.028 & $\beta_{2,40}$ & -0.040 & 0.012 \\
\hline$\beta_{1,9}$ & 0.137 & 0.015 & $\beta_{2,9}$ & 0.045 & 0.030 & $\beta_{2,41}$ & -0.115 & 0.012 \\
\hline$\beta_{1,10}$ & 0.021 & 0.017 & $\beta_{2,10}$ & 0.013 & 0.033 & $\beta_{2,42}$ & -0.528 & 0.013 \\
\hline$\beta_{1,11}$ & -0.078 & 0.019 & $\beta_{2,11}$ & 0.030 & 0.036 & $\beta_{2,43}$ & -0.607 & 0.013 \\
\hline$\beta_{1,12}$ & -0.126 & 0.020 & $\beta_{2,12}$ & 0.039 & 0.039 & Single person & & \\
\hline$\beta_{1,13}$ & -0.093 & 0.021 & $\beta_{2,13}$ & 0.033 & 0.040 & $\beta_{3,1}$ & -0.155 & 0.007 \\
\hline$\beta_{1,14}$ & -0.072 & 0.022 & $\beta_{2,14}$ & 0.120 & 0.043 & Region & & \\
\hline$\beta_{1,15}$ & -0.007 & 0.023 & $\beta_{2,15}$ & 0.095 & 0.044 & $\beta_{3,2}$ & 0.160 & 0.017 \\
\hline$\beta_{1,16}$ & 0.148 & 0.023 & $\beta_{2,16}$ & 0.152 & 0.046 & $\beta_{3,3}$ & 0.092 & 0.012 \\
\hline$\beta_{1,17}$ & 0.083 & 0.025 & $\beta_{2,17}$ & 0.054 & 0.049 & $\beta_{3,4}$ & -0.045 & 0.011 \\
\hline$\beta_{1,18}$ & -0.123 & 0.029 & $\beta_{2,18}$ & 0.081 & 0.056 & $\beta_{3,5}$ & 0.021 & 0.013 \\
\hline$\beta_{1,19}$ & -0.208 & 0.031 & $\beta_{2,19}$ & 0.023 & 0.060 & $\beta_{3,6}$ & 0.024 & 0.010 \\
\hline$\beta_{1,20}$ & -0.123 & 0.032 & $\beta_{2,20}$ & 0.112 & 0.062 & $\beta_{3,7}$ & -0.031 & 0.010 \\
\hline$\beta_{1,21}$ & -0.210 & 0.035 & $\beta_{2,21}$ & 0.017 & 0.070 & $\beta_{3,8}$ & -0.019 & 0.012 \\
\hline$\beta_{1,22}$ & -0.281 & 0.037 & $\beta_{2,22}$ & 0.097 & 0.073 & $\beta_{3,9}$ & 0.005 & 0.013 \\
\hline$\beta_{1,23}$ & -0.355 & 0.040 & $\beta_{2,23}$ & -0.063 & 0.078 & $\beta_{3,10}$ & 0.006 & 0.010 \\
\hline$\beta_{1,24}$ & -0.527 & 0.045 & $\beta_{2,24}$ & -0.071 & 0.086 & Age category & & \\
\hline$\beta_{1,25}$ & -0.401 & 0.043 & $\beta_{2,25}$ & 0.144 & 0.089 & $\beta_{3,11}$ & -0.040 & 0.009 \\
\hline$\beta_{1,26}$ & -0.179 & 0.042 & $\beta_{2,26}$ & -0.146 & 0.087 & $\beta_{3,12}$ & -0.183 & 0.010 \\
\hline$\beta_{1,27}$ & -0.077 & 0.041 & $\beta_{2,27}$ & -0.008 & 0.081 & $\beta_{3,13}$ & -0.234 & 0.012 \\
\hline$\beta_{1,28}$ & -0.229 & 0.047 & $\beta_{2,28}$ & -0.131 & 0.097 & $\beta_{3,14}$ & -0.296 & 0.013 \\
\hline$\beta_{1,29}$ & -0.356 & 0.052 & $\beta_{2,29}$ & 0.031 & 0.106 & $\beta_{3,15}$ & -0.294 & 0.013 \\
\hline$\beta_{1,30}$ & -0.388 & 0.054 & $\beta_{2,30}$ & 0.117 & 0.119 & $\beta_{3,16}$ & -0.310 & 0.014 \\
\hline$\beta_{1,31}$ & 1.118 & 0.211 & $\beta_{2,31}$ & 0.477 & 0.518 & $\beta_{3,17}$ & -0.387 & 0.014 \\
\hline$\beta_{1,32}$ & -0.469 & 0.056 & $\beta_{2,32}$ & -0.176 & 0.139 & $\beta_{3,18}$ & -0.346 & 0.017 \\
\hline \multicolumn{3}{|c|}{ Inflow heterogeneity } & \multicolumn{6}{|c|}{ Unobserved heterogeneity } \\
\hline \multicolumn{3}{|c|}{ Labour market tightness } & \multicolumn{3}{|c|}{ Support points } & & & \\
\hline$\beta_{4,1}$ & -0.201 & 0.012 & $v_{1}$ & 0 & - & & & \\
\hline \multicolumn{3}{|c|}{ Month of inflow } & $v_{2}$ & 0.634 & 0.048 & & & \\
\hline$\beta_{4,2}$ & 0.022 & 0.013 & $v_{3}$ & 1.082 & 0.045 & & & \\
\hline$\beta_{4,3}$ & -0.012 & 0.014 & $v_{4}$ & 1.652 & 0.056 & & & \\
\hline$\beta_{4,4}$ & 0.025 & 0.013 & \multicolumn{6}{|c|}{ Probabilities } \\
\hline$\beta_{4,5}$ & 0.048 & 0.014 & $\pi_{1}$ & 0.363 & 0.030 & & & \\
\hline$\beta_{4,6}$ & 0.080 & 0.013 & $\pi_{2}$ & 0.396 & 0.041 & & & \\
\hline
\end{tabular}


Table 4 continued

\begin{tabular}{|c|c|c|c|c|c|c|c|c|}
\hline \multicolumn{3}{|c|}{ Duration dependence } & \multicolumn{3}{|c|}{$\begin{array}{l}\text { Duration dependence } \\
\times \text { labour market tightness }\end{array}$} & \multicolumn{3}{|c|}{$\begin{array}{l}\text { Seasonal effects } \\
\text { (months of the year) }\end{array}$} \\
\hline Parameter & Estimate & SE & Parameter & Estimate & SE & Parameter & Estimate & SE \\
\hline$\beta_{4,7}$ & 0.064 & 0.013 & $\pi_{3}$ & 0.231 & 0.057 & & & \\
\hline$\beta_{4,8}$ & 0.009 & 0.013 & $\pi_{4}$ & 0.009 & 0.004 & & & \\
\hline$\beta_{4,9}$ & 0.006 & 0.014 & & & & & & \\
\hline$\beta_{4,10}$ & 0.091 & 0.013 & & & & & & \\
\hline$\beta_{4,11}$ & 0.099 & 0.014 & & & & & & \\
\hline$\beta_{4,12}$ & 0.111 & 0.013 & & & & & & \\
\hline
\end{tabular}

These equations define the parameters in the table. The mean log-likelihood function is equal to -2.78561 (222,901 observations)

Table 5 Empirical results when using only individuals who experienced at least two completed unemployment spells

\begin{tabular}{lrrlll}
\hline Time of leaving unemployment & Estimate & SE & Time of entering unemployment & Estimate & SE \\
\hline Business cycle $^{\mathrm{a}}$ & & \multicolumn{5}{c}{ Business cycle $^{\mathrm{a}}$} \\
Tight labour market & 136.9 & 1.54 & Tight labour market & 88.0 & 0.70 \\
Baseline & 100.0 & - & Baseline & 100.0 & - \\
Loose labour market & 73.1 & 0.82 & Loose labour market & 113.6 & 0.90 \\
Season & & & Season & & \\
January & 100.0 & - & January & 100.0 & - \\
February & 83.7 & 1.07 & February & 100.4 & 1.45 \\
March & 77.4 & 1.00 & March & 98.8 & 1.46 \\
April & 97.2 & 1.22 & April & 102.2 & 1.43 \\
May & 78.2 & 1.04 & May & 104.7 & 1.57 \\
June & 73.1 & 0.99 & June & 107.9 & 1.55 \\
July & 90.9 & 1.15 & July & 105.8 & 1.44 \\
August & 78.6 & 1.03 & August & 100.7 & 1.47 \\
September & 97.8 & 1.23 & September & 100.1 & 1.49 \\
October & 89.2 & 1.18 & October & 109.8 & 1.58 \\
November & 58.9 & 0.83 & November & 110.0 & 1.61 \\
December & 54.0 & 0.76 & December & 112.3 & 1.57 \\
Age category (years) & & & & & \\
18-20 & 100.0 & - & & & \\
21-25 & 91.2 & 0.91 & & & \\
26-30 & 79.6 & 0.90 & & & \\
31-35 & 77.3 & 1.00 & & & \\
36-40 & 75.1 & 1.06 & & & \\
41-45 & 77.2 & 1.15 & & & \\
46-50 & 78.3 & 1.24 & & & \\
\hline & & & & & \\
& & & & & \\
& & & & & \\
& & & & & \\
\end{tabular}


Table 5 continued

\begin{tabular}{|c|c|c|c|c|c|}
\hline Time of leaving unemployment & Estimate & SE & Time of entering unemployment & Estimate & SE \\
\hline $51-55$ & 76.7 & 1.27 & & & \\
\hline $56-59$ & 78.0 & 1.58 & & & \\
\hline \multicolumn{6}{|l|}{ Region } \\
\hline South East & 100.0 & - & & & \\
\hline East Anglia & 115.3 & 2.14 & & & \\
\hline South West & 106.6 & 1.35 & & & \\
\hline West Midlands & 94.8 & 1.17 & & & \\
\hline East Midlands & 99.3 & 1.40 & & & \\
\hline Yorkshire and Humberside & 100.3 & 1.14 & & & \\
\hline North West & 95.7 & 1.04 & & & \\
\hline North & 98.7 & 1.29 & & & \\
\hline Wales & 97.2 & 1.42 & & & \\
\hline Scotland & 98.7 & 1.12 & & & \\
\hline \multicolumn{6}{|l|}{ Marital status } \\
\hline Not Single (incl. divorce) & 112.7 & 2.64 & & & \\
\hline Single & 100.0 & - & & & \\
\hline
\end{tabular}

The distribution of unobserved individual heterogeneity

\begin{tabular}{lcclr} 
& Estimate & SE & Probability estimate & SE \\
\hline Support point 1 & 51.0 & 2.49 & 0.44 & 0.022 \\
Support point 2 & 100.0 & - & 0.40 & 0.055 \\
Support point 3 & 151.4 & 9.23 & 0.15 & 0.062 \\
Support point 4 & 235.6 & 19.52 & 0.01 & 0.010 \\
\hline
\end{tabular}

These results are compared with the results in Table 3 that are discussed in Sect. 4. As in Table 3, each cell contains the effect on the baseline hazard of leaving unemployment relative to the baseline hazard of leaving unemployment (set equal to $100 \%$ ). The asterisks show the characteristics of the baseline hazard $S E$ standard error

${ }^{a}$ A loose labour market refers to the 10th percentile, the baseline situation to the 50th percentile and a tight labour market to the 90th percentile of the empirical distribution of labour market tightness

\section{References}

Abbring J, Van den Berg GJ, Van Ours JC (2001) Business cycles and compositional variation in US unemployment. J Bus Econ Stat 19:436-448

Abbring J, Van den Berg GJ, Van Ours JC (2002) The anatomy of unemployment dynamics. Eur Econ Rev 46:1785-1824

Arulampalum W, Stewart MB (1995) The determinants of individual unemployment Durations in an era of high unemployment. Econ J 105(429):321-332

Baker M (1992) Unemployment duration: compositional effects and cyclical variability. Am Econ Rev 82(1):313-321

Baker M, Melino A (2000) Duration dependence and nonparametric heterogeneity: a Monte Carlo study. J Econom 96:357-393

Bell B, Blundell R, Van Reenen J (1999) Getting the unemployed back to work: the role of targeted wage subsidies. Working papers series, no W99/12, The Institute for Fiscal Studies, London 
Blanchard OJ, Diamond P (1994) Ranking, unemployment duration, and wages. Rev Econ Stud 61: 417-434

Butler RJ, McDonald JB (1986) Trends in unemployment duration data. Rev Econ Stat LXVIII(4):545-557

Cockx B, Dejemeppe M (2005) Duration dependence in the exit rate out of unemployment in Belgium Is it True or Spurious. J Appl Econom 20(1):1-23

Darby MR, Haltiwanger JC, Plant M (1985) Unemployment rate dynamics and persistent unemployment under rational expectations. Am Econ Rev 75:614-637

Dolton PJ, O'Neill D (1996) Unemployment duration and the restart effect: some experimental evidence. Econ J 106:387-400

Dolton PJ, Makepeace GH, Treble JG (1994) The youth training scheme and the school-to-work transition. Oxf Econ Pap 46:629-657

Dynarski M, Sheffrin SM (1990) The behavior of unemployment durations over the cycle. Rev Econ Stat 72:350-356

Elbers C, Ridder G (1982) True and spurious duration dependence: the identifiability of the proportional hazard model. Rev Econ Stud 49:403-409

Heckman JJ, Singer B (1984) A method for minimizing the impact of distributional assumptions in econometric models for duration data. Econometrica 52(2):271-320

Honoré BE (1993) Identification results for duration models with multiple spells. Rev Econ Stud 60: 241-246

Huh K, Sickles RC (1994) Estimation of the duration model by nonparametric maximum likelihood, maximum penalized likelihood, and probability simulators. Rev Econ Stat 4:683-694

Imbens GW (1994) Transition models in a non-stationary environment. Rev Econ Stat LXXVI:703-720

Imbens GW, Lynch LM (1993) Re-employment probabilities over the business cycle. Working paper no 4585, National Bureau of Economic Research, USA

Jackman R, Layard R (1991) Does long-term unemployment reduce a Person's chance of a job? A Timeseries Test Economica 58:93-106

Kalwij A (2001) Individuals' unemployment durations over the business cycle. Discussion paper no 369, Institute for the Study of Labor, Bonn

Kalwij A (2004) Individuals' lifecycle unemployment experiences: on the road to stable employment? Oxf Bull Econ Stat 66(2):204-237

Lancaster T (1979) Econometric methods for the duration of unemployment. Econometrica 47(4):939-956

Lancaster T (1990) The econometric analysis of transition data, Econometric society monographs, no 17, Cambridge University Press, Cambridge

Layard R, Nickell S, Jackman R (1991) Unemployment: macroeconomic performance and the labour market. Oxford University Press, New York

Lockwood B (1991) Information externalities in the labour market and the duration of unemployment. Rev Econ Stud 58:733-753

Narendranathan W, Stewart MB (1993a) Modelling the probability of leaving unemployment: competing risks models with flexible baseline hazards. J R Stat Soc Ser C (Appl Stat) 42:63-83

Narendranathan W, Stewart MB (1993b) How does the benefit effect vary as unemployment spells lengthen? J Appl Econom 8:361-381

Nickell S (1999) Unemployment in Britain, chapter 1. In: Gregg P, Wadsworth J (eds) The state of working Britain. Manchester University Press, Manchester

Pissarides CA (1992) Loss of skill during unemployment and the persistence of employment shocks. Q J Econ 107:1371-1391

Pissarides CA (2000) Equilibrium unemployment theory. The MIT Press, London

Rosholm M (2001) Cyclical variation in unemployment duration. J Popul Econ 14:173-191

Salant SW (1977) Search theory and duration data: a theory of sorts. Q J Econ 91(1):39-57

Sider H (1985) Unemployment duration and incidence: 1968-82. Am Econ Rev 75(4):461-472

Sweeney K (1996) Destination of leavers from claimant unemployment. Employment Gazette, October issue, pp 443-452

Turon H (2003) Inflow composition, duration dependence and their impact on the unemployment outflow rate. Oxf Bull Econ Stat 65:31-47

Van den Berg GJ (2001) Duration models: specification, identification, and multiple durations. In: Heckman JJ, Leamer E (eds) Handbook of econometrics, vol V, North-Holland, Amsterdam

Van den Berg GJ, Van der Klaauw B (2001) Combining micro and macro unemployment duration data. J Econom 102:271-309 
Van den Berg GJ, Van Ours JC (1994) Unemployment dynamics and duration dependence in France, The Netherlands and the United Kingdom. Econ J 104:432-443

Vishwanath T (1989) Job search, stigma effect, and escape from unemployment. J Labor Econ 7:487-502

Ward H, Bird D (1995) The JUVOS cohort: a longitudinal database of the claimant unemployed Employment Gazette, September issue, pp 345-350 